meaning after being repeated continuously. Whereas "plant," assumed to have a negligible amount of positive meaning in contrast to "good," will lose its intensity of positive meaning more readily and show less persistence of negligible positive meaning. Perhaps the satiation treatment for "plant" and "good" was contaminated by the differential persistence of the positive meaning of the two words.

The unexpected finding that reinforcer effectiveness is reduced even when the satiated word is different from the word used as the reinforcer, i.e., repetition of the word "plant" appeared to reduce the effectiveness of "good" as a reinforcer, may imply that satiation involves a general nonspecific factor described behaviorally as boredom, a loss of attention, or, more specifically, by habituation of the orienting response (Das, 1966).

The relatively consistent differences obtained between the two words and between the varied durations of repetition (Cook, 1968) pose problems that are unanswerable within the existing theoretical framework employed to explain the satiation effect. The attempts to do so were primarily suggestive. Yet, the results indicate that the satiation effect (1) occurs in very young children, (2) is dependent on the duration of the continued repetition, (3) alters reinforcer's effectiveness, and
(4) may be indexed and assessed by the enhancement or decrement of the effectiveness of a verbal reinforcer in the performance of an operant task.

\section{REFERENCES}

AMSTER, H. Semantic satiation and generation: Learning? Adaptation? Psychological Bulletin, $1964,62,273-286$.

$\mathrm{COOK}, \mathrm{H}$. Verbal satiation of a positive and negative reinforcer in children. Journal of Verbal Learning \& Verbal Behavior, 1968, 7, 1082-1087.

COOK, H., \& VACHON. J. Satiation of a verbal cue in problem solving in French speaking children. Psychonomic Science, 1968, 11, 208.

DAS, J. P. Relation between semantic satiation and verbal conditioning. British Joumal of Psychology, 1966, 57, 87-91.

FILLENBAUM, S. Verbal satiation and changes in meaning related terms. Journal of Verbal Learning \& Verbal Behavior, 1963, 2, 263-271.

GEWIRTZ, J. L. Potency of a social reinforcer as a function of satiation and recovery. Developmental Psychology, 1969, 1, 1-13.

GEWIRTZ, J. L., \& BAER, D. M. Deprivation and satiation of social reinforcers as drive conditions. Journal of Abnormal Social Psychology, 1958, 57, 165-172.

JAKOBOVITS, L. A. Semantic satiation in concept formation. Psychological Reports, $1965,17,113-114$.

JAKOBOVITS, L. A., \& LAMBERT, W. E. Mediated satiation in verbal transfer. Joumal of Experimental Psychology, 1962, 64, 346-351.

ZAJONC, R. B. Attitudinal effects of mere exposure. Journal of Personality \& Social Psychology Monograph Supplement, 1968, 9, (Part 2).

\title{
Interitem interval and total time in
}

serial learning ${ }^{1}$

\begin{abstract}
JAMES M. POLT, Temple Buell College, Denver, Colo. 80220, and KAREN GRIENEEKS, University of Maine, Orono, Maine 04473
\end{abstract}

Eleven groups of 12 Ss each were required to learn a list of eight $C V C$ trigrams presented on a memory drum to a criterion of one perfect trial. The effect of dividing presentation rates of $2,4,8$, and $16 \mathrm{sec}$ into various periods of stimulus duration and interitem (blank) intervals was related to total time to criterion. It was found that the longer presentation rates did not facilitate learning the serial list and that there was a significant drop in efficiency in learning the list at the 16-sec rate. When the stimulus duration was
The second variable dealt with in this study was the rate of item presentation as it affects learning. A number of studies have supported the total-time hypothesis with a wide range of presentation times in paired-association learning (PAL), particularly where the stimulus duration is held constant (Bugelski, 1962, used presentation times that ranged from 6 to $19 \mathrm{sec})$. Cooper \& Pantle (1967), however, noted that while the total-time hypothesis has been supported in SL, the limited range of presentation rates used, typically $2 \mathrm{sec}$ and $4 \mathrm{sec}$, has produced "less impressive" evidence in support of the total-time hypothesis. One study which used a wider range of presentation rates was Fischer (1966). Using times of $2,4,6,8$, and $16 \mathrm{sec}$, her data supported the total-time hypothesis, though learning tended to take longer with the 16 -sec presentation rate.

\section{METHOD}

The apparatus used in this study was a Lafayette memory drum with a variable shutter. A list of eight CVC nonsense syllables selected from Archer (1960), with association values ranging from $48 \%$ to $50 \%$, was presented to 11 groups of $12 \mathrm{Ss}$ each. All Ss were freshman and sophomore women enrolled in introductory psychology courses and were randomly assigned to one of the 11 groups.

Four rates of presentation were used: 2 , 4,8 , and $16 \mathrm{sec}$. Within each presentation rate, the item was present in the window for: (1) the entire period (Groups 2-2, 4-4, $8-8$, and 16-16, with no interitem interval); (2) one-half the period (Groups 2-1, 4-2, $8-4$, and $16-8$, with interitem intervals of 1 , 2,4 , and $8 \mathrm{sec}$, respectively); (3) $1 \mathrm{sec}$ (Groups 2-1, 4-1, 8-1, and 16-1, with interitem intervals of $1,3,7$, and $15 \mathrm{sec}$, respectively).

The Ss were instructed that the syllables would always appear in the same order, that a blank space would occur between syllables (where appropriate), that they were to spell out their anticipations, and that the experiment would continue until they could anticipate each item correctly on a single presentation (i.e., criterion for learning was one perfect trial). An asterisk was used as a cue at the beginning of the list, and all Ss were presented the syllables in the same order.

\section{RESULTS}

The mean total times for learning the list by the various groups are shown in Table 1 . The conventional procedure of presenting serial anticipation lists, with no interval between items, was represented by Groups $2-2,4-4,8-8$, and 16-16 and showed a general decrease in efficiency of time spent learning the list as the presentation rate increased. The exception is a reversal between Groups $4-4$ and $8-8$. The only 
Table 1

Mean Total Time to Learn an Eight-Item List of CVC Nonsense Syllables to a Criterion of One Perfect Trial. Groups are designated by rate of presentation and stimulus duration, with the first number indicating rate of presentation and the second indicating the duration of the stimulus.

\begin{tabular}{lcc}
\hline & $\begin{array}{c}\text { Mean Total- } \\
\text { Time to } \\
\text { Criterion Per } \\
\text { Syllable } \\
\text { (in } \\
\text { Group }\end{array}$ & $\begin{array}{c}\text { Mean Total- } \\
\text { Time for All } \\
\text { Ss un Each } \\
\text { Presentation } \\
\text { Time (in }\end{array}$ \\
\hline $2-2$ & 46.0 & Seconds) \\
$2-1$ & 58.2 & 52.1 \\
$4-4$ & 60.4 & \\
$4-2$ & 65.6 & 62.4 \\
$4-1$ & 61.6 & \\
$8-8$ & 51.2 & \\
$8-4$ & 56.0 & 60.8 \\
$8-1$ & 74.7 & \\
$16-16$ & 70.4 & \\
$16-8$ & 76.8 & 78.4 \\
$16-1$ & 88.0 & \\
\hline
\end{tabular}

significant difference was between Groups 2-2 and 16-16 $(\mathrm{p}=.007$, Mann-Whitney U test).

When the mean time required to learn the list for all $S s$ at each rate of presentation is considered, the three more rapid rates of presentation took significantly less time than the 16-sec rate (2-sec vs 16-sec, p $<.01 ; 4-\mathrm{sec}$ vs $16-\mathrm{sec}$, $\mathrm{p}<.03 ; 8-\mathrm{sec}$ vs $16-\mathrm{sec}, \mathrm{p}=.01$ Mann-Whitney $U$ test). Differences between 2-, 4-, and 8 -sec rates were not significant.

The second common variable among groups was the 1 -sec stimulus duration (Groups 2-1, 4-1, 8-1, and 16-1). As the presentation rate increased, more time was required for learning per syllable with a 1 -sec stimulus duration. Group 2-1 required significantly less time than Group 16-1 $(p=.01)$ and Group 4-1 required significantly less time than Group 16-1 $\quad(\mathrm{p}=.02$, Mann-Whitney $\mathrm{U}$ test). Also, at all rates of presentation, more time was required to learn the list with each item exposed for $1 \mathrm{sec}$ as compared to being available for the total period between items, although this difference was slight between Groups 4-4 and 4-1. The only significant difference between groups with the same rate of presentation was at the 2 -sec rate. The total time required to learn the list was significantly lower for Group $2-2(p=.02$, Mann-Whitney U test).

\section{DISCUSSION}

Comparisons of the mean total time required to learn the list by all Ss at each presentation rate tends to support the total-time hypothesis when applied to SL, with the exception of the 16-sec rate, which required significantly more learning time than did each of the other rates. This would appear to support Fischer's (1966) conclusion that it might be necessary to make adjustments for longer presentation rates to arrive at a valid hypothesis for total learning time in SL. One explanation for the reduced efficiency in learning with longer presentation rates may lie in the fact that on later trials, when the entire list must be repeated in order to pick up one or two syllables, more time will be added to the mean learning time for each syllable in the list with the longer presentation rates.
The seven groups where study time and presentation time are differentiated by an interval between items would indicate that learning is facilitated by the continued presence of the stimulus during the entire interval between items. The question remains as to whether the facilitory effect of a longer stimulus duration occurs as the list is being learned or when items are anticipated after learning. That the only significant difference between groups with the same presentation rates was found between the 2-sec groups would suggest that with longer interitem intervals $(3,4,8$, and $15 \mathrm{sec}$ ) the period is utilized in rehearsal, which is not possible for Group 2-1, with only a 1-sec interval.

\section{REFERENCES}

AARONSON, D. Temporal factors in perception and short-term memory. Psychological Bulletin, 1967, 62, 130-144.

ARCHER, E. J. A re-evaluation of the meaningfulness of all possible CVC trigrams. Psychological Monographs: General and Applied, 1960, 74, 1-22.

BUGELSKI, B. R. Presentation time, total time, and mediation in paired-associate learning. Journal of Experimental Psychology, 1962 , $63,409-412$.

COOPER, E. H., \& PANTLE, A. J. The total-time hypothesis in verbal learning. Psychological Bulletin, 1967, 68, 21-234.

FISCHER, G. J. Relation between stimulus presentation time, serial learning, and the serial-position effect. Journal of Experimental Psychology, 1966, 72, 153-154.

$$
\text { NOTE }
$$

1. A version of this paper was presented at the 1969 meeting of the Rocky Mountain Psychological Association by the junior author. This research was in part supported by NSF Undergraduate Research Participation Grant No. GY5871, awarded to Temple Buell College. 